GRADIATION\&APPLICATIONS

ISSN 2466-4294 (online) | rad-journal.org

Vol. 2 | Issue 1 | pp. $41-45$

doi: 10.21175/RadJ.2017.01.009

Original research paper

\title{
CORROSION INHIBITION OF MILD STEEL IN AQUEOUS SULFURIC ACID SOLUTION USING HETEROCYCLIC MERCAPTO COMPOUNDS- AN EXPERIMENTAL AND THEORETICAL STUDY *
}

\author{
Valbonë Mehmeti', Kurt Kalcher², Fetah Podvorica', AvniBerisha ${ }^{1^{* *}}$ \\ ${ }^{1}$ University of Pristina, FNMS, Department of Chemistry, Pristina, Kosovo ${ }^{* * *}$ \\ ${ }^{2}$ University of Graz, Department of Chemistry, Graz, Austria
}

\begin{abstract}
The corrosion behavior of iron in o.1M aqueous sulfuric acid medium has been studied in the presence and absence of: 4-methyl-4H-1,2,4-triazole-3-thiol and 2-mercaptonicotinic acid. Potentiodynamic measurements did not show any shift of corrosion potential toward a more negative potential indicating that these compounds mostly act as mixed inhibitors due to their adsorption on the iron surface. The adsorbed film of these molecules hinders the transport of the metal ions from the metal to the solution and also retards the hydrogen evolution reaction by acting as a physical barrier. The molecules were also studied with the density functional theory (DFT), using the B3LYP functional in order to determine the relationship between the molecular structure and the corrosion inhibition behavior.
\end{abstract}

Key words: Mild steel, corrosion inhibitors, quantum methods, mercapto compounds

\section{INTRODUCTION}

Mild steel is broadly a valuable constructional material used in myriad diverse industries mostly due to its excellent mechanical properties and its low cost. The central problem with this material and generally with other metals is their vulnerability to corrosion, hence their surface must be protected from this undesired process. The protection of metals, apart from the use of classic inhibitors [1-7], can be also accomplished through the employment of surface modification strategies via chemical or electrochemical methods such SAM's (Self Assembled Monolayers) formed from silanes [8,9], phosphonic acids [10,11], sodium oleate [12] or electrochemical reduction of aryldiazonium salts on metals $[13,15]$, with the exclusion of 2,6-dimethylbenzene diazonium salt [15]. Nearly all of the important acid inhibitors are organic compounds containing $\mathrm{N}, \mathrm{O}, \mathrm{P}, \mathrm{S}$, and aromatic ring or triple bonds. It was proclaimed previously that the inhibition efficiency decreases in the order: $\mathrm{O}>\mathrm{N}>\mathrm{S}>\mathrm{P}$ $[3,4]$. Density functional theory has become a convenient method to decipher experimental results, permitting one to obtain structural parameters for molecules [3]. In corrosion studies, this method makes it possible to accurately predict the inhibition efficacy of organic corrosion inhibitors based on electronic/molecular properties and reactivity indices [16]. In this study two different mercapto compounds: a) 2-mercaptonicotinic acid (2MA) and b) 4-methyl$4 \mathrm{H}-1,2,4$-triazole-3-thiol (4MT) were used as corrosion inhibitors for mild steel in 0.1M sulfuric acid solution. The adsorption mechanism and inhibition performance of $4 \mathrm{MT}$ and $2 \mathrm{MA}$ acid were investigated as corrosion inhibitors using DFT at the B3LYP/6-31G(d,p) basis set level.

\section{EXPERIMENTAL}

For the electrochemical measurements the electrode was prepared by embedment of mild steel wire $(\mathrm{d}=2 \mathrm{~mm}, \mathrm{l}=1 \mathrm{Omm})$ inside a Teflon ${ }^{\circledR}(\mathrm{d}=1 \mathrm{~cm}, \mathrm{l}=6$ $\mathrm{cm}$ ) tube by epoxy resin. Prior to its use, the electrode was polished on silicon carbide abrasive paper (median grain diameter $6.5-15.3$ microns), passed onto second polishing cloth (DP-Nap) which was wetted by aluminum oxide ( 0.3 micron particle size), then the electrode was washed and sonicated in water. The chemical composition of the electrode was as follows: iron $99.5494 \%$, carbon $0.1252 \%$, phosphorous 0.0316 $\%$, manganese $0.1831 \%$, silicon $0.0561 \%$, chromium

* The paper was presented at the Fourth International Conference on Radiation and Applications in Various Fields of Research (RAD 2016), Niš, Serbia, 2016.

***avniberisha83@gmail.com

**** This definition does not prejudge the position of status in accordance with UNSC Resolution 1244 and the International Court of Justice on Kosovo's Declaration of Independence 
$0.0124 \%$, sulfur $0.0282 \%$, molybdenum $0.0125 \%$ and nickel $0.0015 \%$.

\subsection{Electrochemical test}

The electrochemical studies were carried out with PalmSens ${ }^{3}$ potentiostat in a traditional three-electrode cell at $298 \mathrm{~K}$. A graphite $\operatorname{rod}(\mathrm{d}=3 \mathrm{~mm}, \mathrm{l}=4 \mathrm{~cm})$ and a saturated calomel electrode (SCE) were used as auxiliary and reference electrode, respectively.

The potentiodynamic polarization curves were obtained by scanning the electrode potential several hundred $\mathrm{mV}$ versus EocP with a sweep rate of $1 \mathrm{mVs}^{-1}$. All experiments were performed under atmospheric conditions. Each experiment was repeated at least three times to check the reproducibility.

\subsection{Computational details}

The calculations presented here were performed by using DFT method with the B3LYP functional using the $6-31 \mathrm{G}^{*}$. This method permits calculating, in a reproducible manner, the molecular parameters (electronegativity, global hardness and softness, electron affinity and ionization potential may well be defined in relation to the energy of the HOMO and the LUMO, etc.) [3,16-18]. Some of the mentioned parameters, their meaning and the equations for their calculations are presented in the table below:

Table 1. Some parameters, their meaning and equations for their calculation

\begin{tabular}{|c|c|}
\hline Formula & Meaning \\
\hline & Electronegativity (X) is \\
\hline$X \approx-1 / 2\left(E_{\text {Hомо }}+E_{L U M O}\right)$ & of an electron or a group \\
\hline & $\begin{array}{l}\text { of atoms to attract } \\
\text { electrons towards itself }\end{array}$ \\
\hline & Chemical hardness $(\eta)$ is \\
\hline$\eta \approx-1 / 2\left(E_{H о м о-E_{L U M O}}\right)$ & $\begin{array}{l}\text { resistance of an atom to a } \\
\text { charge transfer }\end{array}$ \\
\hline & $\begin{array}{l}\text { Chemical softness }(\sigma) \text { is } \\
\text { the measure of the }\end{array}$ \\
\hline $\begin{array}{c}\sigma \approx 1 / \eta=-2\left(E_{\text {номо }}-\right. \\
\left.E_{L U M о}\right)\end{array}$ & $\begin{array}{l}\text { capacity of an atom or a } \\
\text { group of atoms to receive } \\
\text { electrons }\end{array}$ \\
\hline$I \approx-E_{\text {Номо }}$ & $\begin{array}{l}\text { Ionization potential (I) is } \\
\text { defined as the amount of } \\
\text { energy required to } \\
\text { remove an electron from a } \\
\text { molecule }\end{array}$ \\
\hline$A \approx-E_{L U M O}$ & $\begin{array}{l}\text { Electron affinity }(\mathrm{A}) \text { is } \\
\text { defined as the energy } \\
\text { released when a proton is } \\
\text { added to a system. }\end{array}$ \\
\hline
\end{tabular}

\section{RESULTS AND DISCUSSION}

In Fig. 1 and 2, the anodic and cathodic polarization curves of mild steel electrode ino.1 $\mathrm{M} \mathrm{H}_{2} \mathrm{SO}_{4}$ solution are presented in the absence and presence of $1^{*} 10^{-3} \mathrm{M}$, $1^{*} 10^{-4} \mathrm{M}$ of $2-\mathrm{MA}$ and $4 \mathrm{MT}$, respectively, at $298 \mathrm{~K}$. The IE (\%) was calculated using the following equation:

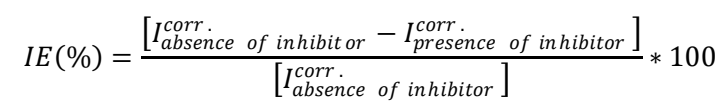

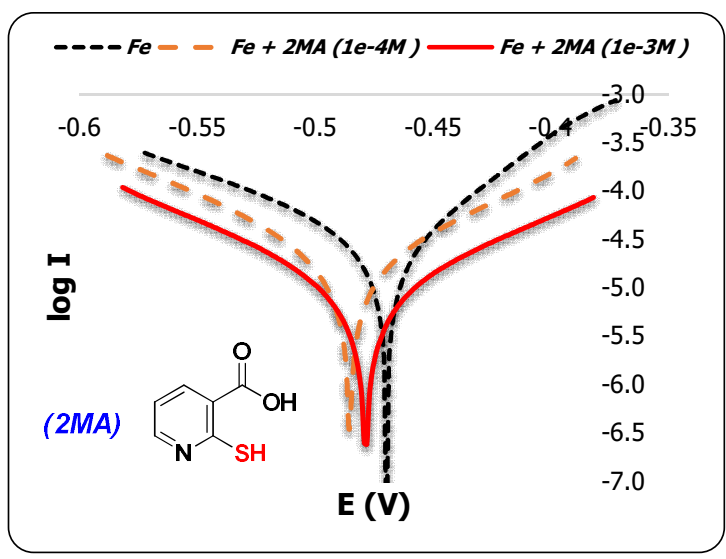

Figure 1. The Tafel plot of the mild steel electrode measured in $0.1 \mathrm{M} \mathrm{H}_{2} \mathrm{SO}_{4}$ solution: in the absence and in the presence of $1^{*} 10^{-3} \mathrm{M}$ and $1^{*} 10^{-4} \mathrm{M}$ of 2-mercaptonicotinic acid (2MA).

The values of electrochemical parameters, such as corrosion potential (Ecorr) and corrosion current density ( $\mathrm{I}_{\text {corr }}$ ), were determined from the intersection of anodic and cathodic Tafel slopes and are shown in Table 2. From the Tafel plot in Fig. 1 and Fig. 2, it's evident that the adsorption of the 2-MA and 4MT respectively, molecules onto the mild steel surface immensely lowers the corrosion current of the $\mathrm{m}$ in this aggressive media, reflecting a high value of the corrosion inhibition efficiency up to $70.13 \%$ for the 2MA molecule and $63.17 \%$ 4MT when both used at 1e$3 \mathrm{M}$.

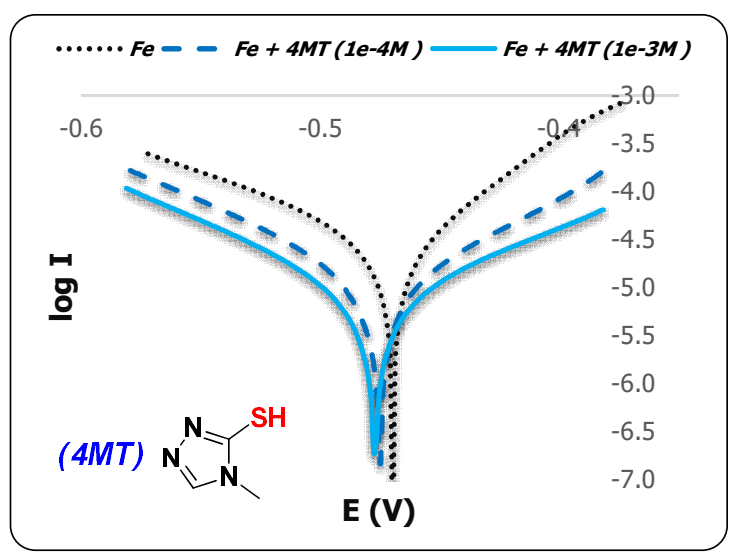

Figure 2. The Tafel plot of the mild steel electrode measured in $0.1 \mathrm{M} \mathrm{H}_{2} \mathrm{SO}_{4}$ solution: in the absence and in the presence of $1^{*} 10^{-3} \mathrm{M}$ and $1^{*} 10^{-4} \mathrm{M}$ of 4 -methyl-4H-1,2,4-triazole-3-thiol (4MT).

The Resistance of the polarization (Rp) from Tafel extrapolation method was calculated using the SternGeary Equation [19]:

$$
\boldsymbol{R}_{p}=\frac{\boldsymbol{\beta}_{a} * \boldsymbol{\beta}_{c}}{2.303\left(\beta_{a}+\beta_{c}\right)} * \frac{1}{I_{c o r r}}
$$


In Table 2, it can be seen that by increasing the inhibitor concentration, the polarization resistance increases in the presence of both of the compounds, implying the adsorption of the inhibitor on the metal surface which blocks the active sites efficiently and inhibits corrosion $[4,20]$.

Table 2. The inhibition efficiency and other electrochemical parameters of the 2MA and $4 \mathrm{MT}$ inhibitors at $1^{*} 10^{-3} \mathrm{M}$ and 1*10-4 $\mathrm{M}$ toward the mild steel in $0.1 \mathrm{M} \mathrm{H}_{2} \mathrm{SO}_{4}$ corrosion media.

\begin{tabular}{c|ccccc} 
Parameters & Fe & $\begin{array}{c}1 \mathrm{e}-4 \mathrm{M} \\
4 \mathrm{MT}\end{array}$ & $\begin{array}{c}1 \mathrm{e}-3 \mathrm{M} \\
4 \mathrm{MT}\end{array}$ & $\begin{array}{c}1 \mathrm{e}-4 \mathrm{M} \\
2 \mathrm{MA}\end{array}$ & $\begin{array}{c}1 \mathrm{e}-3 \mathrm{M} \\
2 \mathrm{MA}\end{array}$ \\
\hline $\mathrm{bc}(\mathrm{V} / \mathrm{dec})$ & 0.058 & 0.092 & 0.089 & 0.090 & 0.097 \\
\hline $\mathrm{ba}(\mathrm{V} / \mathrm{dec})$ & 0.103 & 0.082 & 0.090 & 0.074 & 0.115 \\
\hline Ecorr $(\mathrm{V})$ & -0.470 & -0.484 & -0.478 & -0.475 & -0.477 \\
\hline $\mathrm{Rp}(\Omega)$ & 639.4 & 2471.7 & 2579.8 & 1787.4 & 2467.6 \\
IE $(\%)$ & - & $\mathbf{6 3 . 1 3}$ & $\mathbf{7 0 . 1 3}$ & $\mathbf{6 1 . 0 3}$ & $\mathbf{6 3 . 1 7}$
\end{tabular}

The values of cathodic and anodic Tafel slope (bc,ba) for both of studied molecules are found to change in the presence of the inhibitor. The Tafel slope variations suggest that both compounds influence the kinetics of the hydrogen evolution reaction [21]. This indicates an increase in the energy barrier for proton discharge, leading to less gas evolution [5].

Regarding the corrosion potential, the studied molecules almost do not change it, thus they express a behavior of a mixed inhibitor [3].

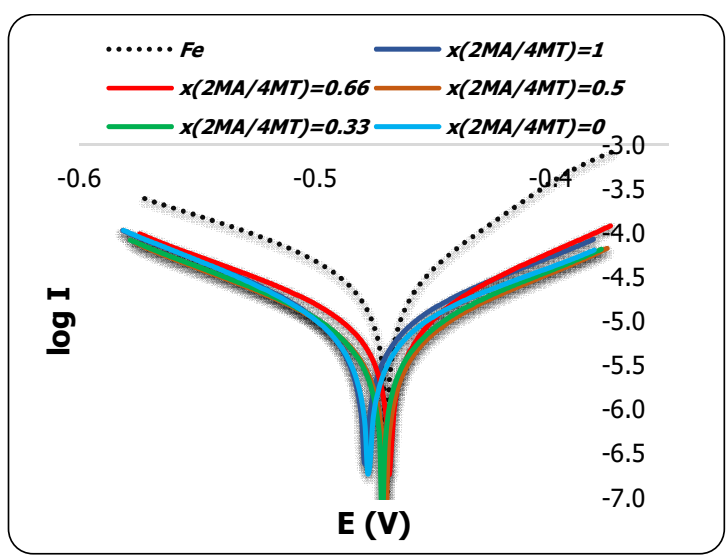

Figure 3. The Tafel plot of the mild steel electrode measured in $0.1 \mathrm{M} \mathrm{H}_{2} \mathrm{SO}_{4}$ solution: in the absence and in the presence of different molar ratio of $\mathrm{x}(2-\mathrm{MA} /(4 \mathrm{MT})=1,0.66,0.5,0.33$ and $\mathrm{O}\left(\mathrm{c}=1^{*} 1 \mathrm{O}^{-3} \mathrm{M}\right.$ for both of the molecules).

From the data presented in Table 3, it is obvious that the use of the mixed inhibitors in fact does not have an important impact on the IE.

Table 3. The inhibition efficiency of the mixed inhibitors (2MA/4MT) at different molar ratios from o to 1 (each $1^{*} 10^{-3}$ M) toward the mild steel in $0.1 \mathrm{M} \mathrm{H}_{2} \mathrm{SO}_{4}$ corrosion media.

\begin{tabular}{c|cccccc}
\multirow{2}{*}{ Parameters } & Fe & \multicolumn{6}{|c}{$\mathbf{x ( 2 M A / 4 M T )}$} \\
\cline { 2 - 7 } bc $(\mathrm{V} / \mathrm{dec})$ & 0.058 & 0.089 & 0.098 & 0.109 & 0.109 & 0.097 \\
\hline $\mathrm{ba}(\mathrm{V} / \mathrm{dec})$ & 0.103 & 0.090 & 0.082 & 0.103 & 0.105 & 0.115 \\
Ecorr $(\mathrm{V})$ & -0.470 & -0.478 & -0.468 & -0.470 & -0.471 & -0.477 \\
Rp $(\Omega)$ & 639.4 & 2579.8 & 2284.8 & 2977.1 & 2801.3 & 2467.6 \\
\hline IE $(\%)$ & - & $\mathbf{7 0 . 1 3}$ & $\mathbf{6 6 . 2 0}$ & $\mathbf{6 9 . 4 4}$ & $\mathbf{6 7 . 1 8}$ & $\mathbf{6 3 . 1 7}$
\end{tabular}
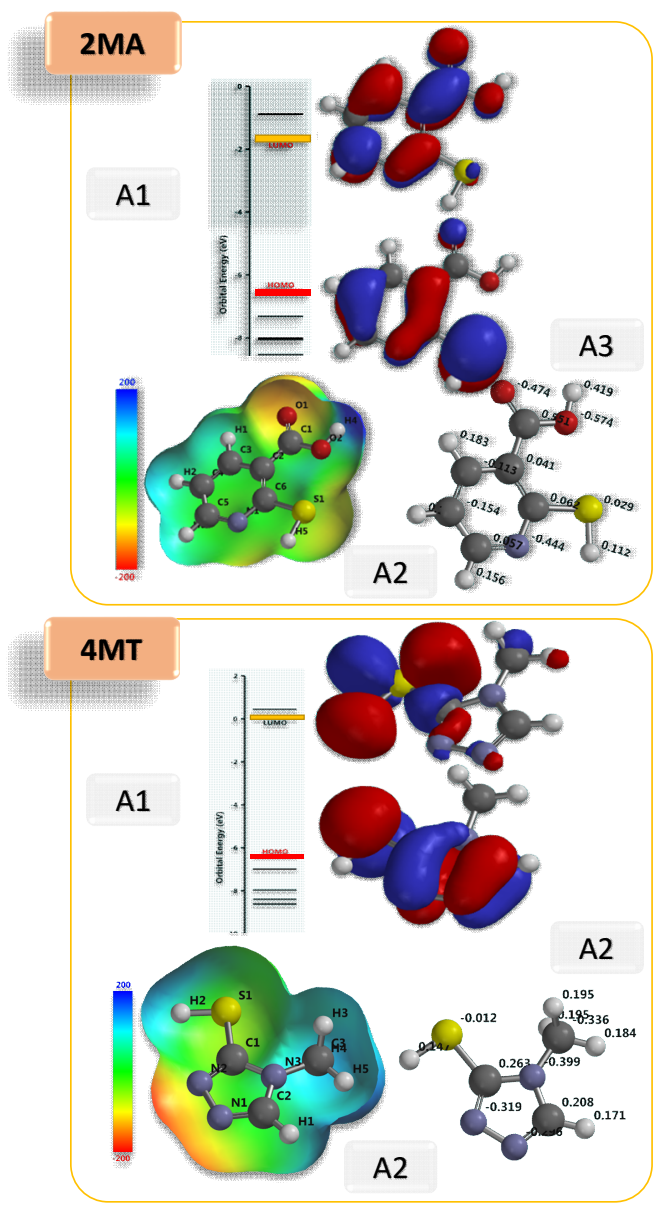

Figure 4. Optimized structures: A1. HOMO and LUMO A2. Electrostatic potential map and A3. Mulliken charge for 2MA and 4MT molecules. (B3LYP/6-31G* results in vacuo).

The shape and symmetry of the HOMO and the LUMO are the central parameters for the estimation of the reactivity of a molecule $[16,18]$. The analysis of the HOMO indicates the regions of the molecule that have a tendency to donate electrons to electrophilic species while the analysis of the LUMO predicts the regions of the molecule with high tendency to accept electrons from nucleophilic species. In 2MA (Fig.4), the HOMO orbital has the highest distribution on the N1-C6, C4C5single bonds and $\mathrm{C}_{2}=\mathrm{C} 6$ double bond, which implies that these are the regions of the molecule with the highest tendency to donate electrons; the LUMO is localized on $\mathrm{C}_{3}, \mathrm{C}_{5}$ and $\mathrm{C} 6$ atoms. In 4MT molecule, the HOMO orbital is spread in the region between the $\mathrm{C}_{2}-\mathrm{N}_{3}, \mathrm{~N}_{1}-\mathrm{N} 2$ single bonds, $\mathrm{C}_{2}=\mathrm{N}_{1}$ double bond and $\mathrm{S}$ atom; the LUMO is strongly localized at the part of $\mathrm{SH}$ group. Ionization potential is directly related to the energy of HOMO orbital and the electron affinity is dependent on the energy of LUMO orbital. Our results show that the HOMO and the LUMO are delocalized throughout the study. The energy of the HOMO shows the capability of the molecule to donate electrons. The molecule with the higher $\mathrm{E}_{\text {Hомо }}$ has electrons with higher energy and therefore it can easily share these electrons with other species. In the investigated 
compounds (Table 4), the Eномо is larger in $4 \mathrm{MT}$, consequently 4MT should have the highest tendency to adsorb onto the metal surface and to provide electrons the lone pair electrons on $\mathrm{S}$ and $\mathrm{N}$ atoms to the unoccupied iron d-orbital [6].

Table 4. The molecular properties for the investigated compounds using: DFT, B3LYP/6-31G (d,p). Results in vacuo. All energies are in $\mathrm{eV}$.

\begin{tabular}{c|cc}
\hline Molecule & $4 M T$ & $2 M A$ \\
\hline $\mathrm{E}_{\text {(номо })}$ & -6.470 & -6.370 \\
$\mathrm{E}_{\text {(LUMO) }}$ & -1.720 & 0.020 \\
$\Delta \mathrm{E}$ & -4.750 & -6.390 \\
$\mu$ & 1.060 & 4.920 \\
$\mathrm{IP}$ & 6.470 & 6.370 \\
$\mathrm{EA}$ & 1.720 & -0.020 \\
$\chi$ & 4.095 & 3.175 \\
$\eta$ & 2.375 & 3.195 \\
$\sigma$ & 0.421 & 0.313 \\
$\omega$ & 0.237 & 3.788 \\
\hline
\end{tabular}

The $\sigma$ value for the investigated compounds is the highest for $4 \mathrm{MT}>2 \mathrm{MA}$ which fully agrees with the experimentally determined inhibition efficiency of the inhibitors. The dipole moment tells about the polarity of the molecule. Numerous researchers in the area of corrosion science have established that an increase in the inhibition efficiency is related to the increase in the dipole moment [3,7].The dipole moment for the studied compounds is the highest for $4 \mathrm{MT}$, which concedes well with our experimental results. Some molecular properties do not only indicate the reactivity of molecules but also indicate the site selectivity in individual chemical species, i.e. the regions of the molecules on which certain types of reactions are likely to occur. The partial atomic charge on the atoms of the molecule is one of such parameters. The interaction between the metal and the inhibitor is often considered to preferentially take place on the atom with the highest negative charge. The Mulliken atomic charges for the studied compounds are reported in Fig. 4 and the highest negative charge on both of the molecules is located on the heteroatoms, which suggests that these centers have the highest electron density and would preferentially interact with the metal surface.

\section{CONCLUSION}

The inhibition efficiency of: 4-methyl-4H-1,2,4triazole-3-thiol (4MT) and 2-mercaptonicotinic acid (2MA)has been investigated by experimental techniques and quantum chemical approaches. Potentiodynamic measurements put in evidence the inhibitor properties of these molecules toward mild steel corrosion in aqueous acid medium. The quantum chemical calculations revealed information about the active centers (of the compounds) which would likely interact with the metal surface. The analysis of the HOMO and the LUMO orbital energies showed the possible electron-donating centers on the inhibitor molecules and this tendency is also confirmed by calculating charges on the atoms. Experimental and theoretical results show that the inhibition efficiency is the highest for 4-methyl-4H-1,2,4-triazole-3-thiol (4MT), and this value is in good agreement with the calculated Mulliken charges which impose that three nitrogen atoms are more prone to adsorption on the iron surface and thus have a greater impact on corrosion inhibition efficiency. All of the calculated theoretical parameters [energy of the HOMO (Еномо), the energy of the LUMO ( $\mathrm{E}_{\mathrm{LUMO}}$ ), the energy difference between the HOMO and the LUMO $(\Delta \mathrm{E})$, global hardness $(\eta)$, global softness $(\sigma)$ and the dipole moment $(\mu)]$ are in full agreement with the experimental results.

\section{REFERENCES}

1. M. Finšgar and J. Jackson, "Application of corrosion inhibitors for steels in acidic media for the oil and gas industry: A review," Corros. Sci., vol. 86, pp. 17-41, Sep. 2014. DOI: 10.1016/j.corsci.2014.04.044

2. B. Sanyal, "Organic compounds as corrosion inhibitors in different environments - A review," Prog. Org. Coatings, vol. 9, no. 2, pp. 165-236, Aug. 1981. DOI: 10.1016/0033-0655(81)80009-X

3. A. Berisha, F. Podvorica, V. Mehmeti, F. Syla, and D. Vataj, "Theoretical and experimental studies of the corrosion behavior of some thiazole derivatives toward mild steel in sulfuric acid media," Macedonian Journal of Chemistry and Chemical Engineering, vol. 34, no. 2. pp. 287-294, Nov. 2015.

DOI: $10.20450 / \mathrm{mjcce} .2015 .576$

4. F. Mohsenifar, H. Jafari, and K. Sayin, "Investigation of Thermodynamic Parameters for Steel Corrosion in Acidic Solution in the Presence of $\mathrm{N}, \mathrm{N}^{\prime}-$ Bis(phloroacetophenone)-1,2 propanediamine," J. BioTribo-Corrosion, vol. 2, no. 1, p. 1, Mar. 2016. DOI: $10.1007 / \mathrm{s} 40735-015-0031-y$

5. S. Tamil Selvi, V. Raman, and N. Rajendran, "Corrosion inhibition of mild steel by benzotriazole derivatives in acidic medium," J. Appl. Electrochem., vol. 33, no. 12, pp. 1175-1182, Dec. 2003.

DOI: 10.1023/B:JACH.oooooo3852.38068.3f

6. A. S. Fouda and A. S. Ellithy, "Inhibition effect of 4phenylthiazole derivatives on corrosion of 304L stainless steel in $\mathrm{HCl}$ solution," Corros. Sci., vol. 51, no. 4, pp. 868-875, Apr. 2009. DOI: 10.1016/j.corsci.2009.01.011

7. S N. O. Obi-Egbedi, I. B. Obot, and M. I. El-Khaiary, "Quantum chemical investigation and statistical analysis of the relationship between corrosion inhibition efficiency and molecular structure of xanthene and its derivatives on mild steel in sulphuric acid," J. Mol. Struct., vol. 1002, no. 1-3, pp. 86-96, Sep. 2011. DOI: 10.1016/j.molstruc.2011.07.003

8. W. J. van Ooij, D. Zhu, M. Stacy, A. Seth, T. Mugada, J. Gandhi, and P. Puomi, "Corrosion protection properties of organofunctional silanes - An overview," Tsinghua Sci. Technol., vol. 10, no. 6, pp. 639-664, Dec. 2005. DOI: 10.1016/S1007-0214(05)70134-6

9. V. Palanivel, Y. Huang, and W. J. van Ooij, "Effects of addition of corrosion inhibitors to silane films on the performance of AA2024-T3 in a $0.5 \mathrm{M} \mathrm{NaCl}$ solution," Prog. Org. Coatings, vol. 53, no. 2, pp. 153-168, Jun. 2005.

DOI: 10.1016/j.porgcoat.2003.07.008 
10. M. Kosian, M. M. J. Smulders, and H. Zuilhof, "Structure and Long-Term Stability of Alkylphosphonic Acid Monolayers on SS316L Stainless Steel," Langmuir, vol. 32, no. 4, pp. 1047-57, Feb. 2016. DOI: 10.1021/acs.langmuir.5bo4217 PMid: 26771302

11. T. Abohalkuma and J. Telegdi, "Corrosion protection of carbon steel by special phosphonic acid nano-layers," Mater. Corros., vol. 66, no. 12, pp. 1382-1390, Dec. 2015. DOI: $10.1002 / \mathrm{maco} .201508304$

12. H. N. Shubha, T. V Venkatesha, K. Vathsala, M. K. Pavitra, and M. K. P. Kumar, "Preparation of self assembled sodium oleate monolayer on mild steel and its corrosion inhibition behavior in saline water," $A C S$ Appl. Mater. Interfaces, vol. 5, no. 21, pp. 10738-44, Nov. 2013.

DOI: $10.1021 / \mathrm{am} 4028857$ PMid: 24144468

13. F. I. Podvorica, C. Combellas, M. Delamar, F. Kanoufi, and J. Pinson, "Spontaneous grafting of iron surfaces by reduction of aryldiazonium salts in acidic water. Applications to the inhibition of iron corrosion," in Passivation of Metals and Semiconductors, and Properties of Thin Oxide Layers, eds. P. Marcus, V. Maurice, Amsterdam, The Netherlands: Elsevier, 2006. pp. 697-702.

DOI: 10.1016/B978-044452224-5/50106-2

14. A. Berisha, M. Chehimi, J. Pinson, and F. Podvorica, "Electrode surface modification using diazonium salts," in Electroanalytical Chemistry: A Series of Advances: Volume 26, eds. A. J. Bard, C. G. Zoski, CRC Press, 2015, pp. 115-224. DOI: $10.1201 / \mathrm{b} 19196-4$

15. A. Berisha, C. Combellas, F. Kanoufi, J. Pinson, and F. I. Podvorica, "Physisorption vs grafting of aryldiazonium salts onto iron: A corrosion study," Electrochim. Acta, vol. 56, no. 28, pp. 10762-10766, Dec. 2011.

DOI: 10.1016/j.electacta.2011.01.049
16. I. B. Obot, D. D. Macdonald, and Z. M. Gasem, "Density functional theory (DFT) as a powerful tool for designing new organic corrosion inhibitors. Part 1: An overview," Corros. Sci., vol. 99, pp. 1-30, Jan. 2015. DOI: 10.1016/j.corsci.2015.01.037

17. P. Geerlings, F. De Proft, and W. Langenaeker, "Conceptual Density Functional Theory," Chem. Rev. vol. 103, no. 5, pp. 1793-1874, May 2003. DOI: $10.1021 /$ cr990029p

PMid: 12744694

18. G. Gece, "The use of quantum chemical methods in corrosion inhibitor studies," Corros. Sci., vol. 50, no. 11, pp. 2981-2992, Nov. 2008. DOI: 10.1016/j.corsci.2008.08.043

19. L. Larabi, Y. Harek, M. Traisnel, and A. Mansri, "Synergistic influence of poly(4-Vinylpyridine) and potassium iodide on inhibition of corrosion of mild steel in $1 \mathrm{M} \mathrm{HCl,"} \mathrm{J.} \mathrm{Appl.} \mathrm{Electrochem.,} \mathrm{vol.} \mathrm{34,} \mathrm{no.} \mathrm{8,}$ pp. 833-839, Aug. 2004. DOI: 10.1023/B:JACH.0000035609.09564.e6

20. F. Mansfeld, M. W. Kendig, and S. Tsai, "Recording and analysis of AC impedance data for corrosion studies," Corrosion, vol. 38, no. 11, pp. 570-580, Mar. 1982. DOI: 10.5006/1.3577304

21. G. Quartarone, L. Bonaldo, and C. Tortato, "Inhibitive action of indole-5-carboxylic acid towards corrosion of mild steel in deaerated 0.5M sulfuric acid solutions," Appl. Surf. Sci., vol. 252, no. 23, pp. 8251-8257, Sep. 2006.

DOI: 10.1016/j.apsusc.2005.10.051

22. A. Yurt, S. Ulutas, and H. Dal, "Electrochemical and theoretical investigation on the corrosion of aluminium in acidic solution containing some Schiff bases," Appl. Surf. Sci., vol. 253, no. 2, pp. 919-925, Nov. 2006.

DOI: 10.1016/j.apsusc.2006.01.026 